\title{
Adjacent-segment disease after thoracic pedicle screw fixation
}

\author{
Nitin Agarwal, MD, ${ }^{1}$ Robert F. Heary, MD, ${ }^{2}$ and Prateek Agarwal, $A B^{3}$ \\ ${ }^{1}$ Department of Neurological Surgery, University of Pittsburgh Medical Center, Pittsburgh, Pennsylvania; ${ }^{2}$ Department of \\ Neurological Surgery, Rutgers New Jersey Medical School, Newark, New Jersey; and ${ }^{3}$ Perelman School of Medicine, University \\ of Pennsylvania, Philadelphia, Pennsylvania
}

OBJECTIVE Pedicle screw fixation is a technique widely used to treat conditions ranging from spine deformity to fracture stabilization. Pedicle screws have been used traditionally in the lumbar spine; however, they are now being used with increasing frequency in the thoracic spine as a more favorable alternative to hooks, wires, or cables. Although safety concerns, such as the incidence of adjacent-segment disease (ASD) after cervical and lumbar fusions, have been reported, such issues in the thoracic spine have yet to be addressed thoroughly. Here, the authors review the literature on ASD after thoracic pedicle screw fixation and report their own experience specifically involving the use of pedicle screws in the thoracic spine.

METHODS Select references from online databases, such as PubMed (provided by the US National Library of Medicine at the National Institutes of Health), were used to survey the literature concerning ASD after thoracic pedicle screw fixation. To include the authors' experience at Rutgers New Jersey Medical School, a retrospective review of a prospectively maintained database was performed to determine the incidence of complications over a 13-year period in 123 consecutive adult patients who underwent thoracic pedicle screw fixation. Children, pregnant or lactating women, and prisoners were excluded from the review. By comparing preoperative and postoperative radiographic images, the occurrence of thoracic ASD and disease within the surgical construct was determined.

RESULTS Definitive radiographic fusion was detected in 115 (93.5\%) patients. Seven incidences of instrumentation failure and 8 lucencies surrounding the screws were observed. One patient was observed to have ASD of the thoracic spine. The mean follow-up duration was 50 months.

CONCLUSIONS This long-term radiographic evaluation revealed the use of pedicle screws for thoracic fixation to be an effective stabilization modality. In particular, ASD seems to be less of a problem in the relatively immobile thoracic spine than in the more mobile cervical and lumbar spines.

https://thejns.org/doi/abs/10.3171/2017.6.SPINE1492

KEY WORDS pedicle screw fixation; thoracic fusion; adjacent-segment disease

$\mathrm{P}$ EDICLE screw fixation is a frequently used surgical technique for treating conditions ranging from spine deformity to fracture stabilization. $7,12,23,27,43,44$, ${ }^{50,69}$ Previous publications have reported pedicle screw instrumentation to be both biomechanically and clinically superior to the use of hooks in spinal surgery. ${ }^{34,35,37,42,43,65,70}$ Pedicle screws, compared with hooks, have a demonstrated higher stiffness and improved pullout strength. ${ }^{4,28}$ Furthermore, the use of pedicle screws in surgery to treat spinal deformity has been found to result in lower complication rates and better 3D correction and enables shorter fusion lengths than the use of hooks. ${ }^{4,7,8,28,59}$
For the past several decades, pedicle screws have been used in the lumbar spine and yield numerous clinical benefits. $7,8,11,18,20,27,28,33,43,47,59,66$ Also, pedicle screw fixation has become a favorable alternative to hook and/or wire/cable fixation in the thoracic spine. ${ }^{5,50,57,58,68}$ First proposed by Suk et al. ${ }^{58}$ in 1995 for the treatment of adolescent idiopathic scoliosis, thoracic pedicle screws have been reported to produce better biomechanical and clinical outcomes than do hooks. These benefits include thoracic and apical rotational capabilities, torsional strength, and clinical outcomes that are better than those obtained with other hybrid constructs. ${ }^{6,15,34,36-38,46,56}$

ABBREVIATIONS ASD = adjacent-segment disease; $\mathrm{PJK}=$ proximal junctional kyphosis; $\mathrm{SVA}=$ sagittal vertical axis .

SUBMITTED January 26, 2014. ACCEPTED June 8, 2017.

INCLUDE WHEN CITING Published online December 15, 2017; DOI: 10.3171/2017.6.SPINE1492. 
On December 30, 2016, after a comprehensive review process, the FDA formally reclassified pedicle screws from class III to class II devices. This reclassification indicates recognition by the FDA that pedicle screws are a reasonable surgical alternative, thereby enabling increased education and use. Greater use of thoracic pedicle screws in fusion surgeries necessitates that any potential safety concerns about and complications from such instrumentation be thoroughly addressed.

Previous studies have reported complications such as screw misplacement, pedicle fractures, and dural violations in association with the use of thoracic pedicle screws. ${ }^{14}$ In addition to impairing the pullout strength, screw misplacement can lead to damage to neurological, vascular, and visceral structures. ${ }^{16,17,44,63,64}$ Numerous studies have found vital neurological and vascular structures to be at risk during thoracic pedicle screw instrumentation. ${ }^{13,63,64}$ Because of the proximity of these neurovascular structures to the thoracic spine, an increased risk for complications such as nerve root and/or spinal cord injury exists. ${ }^{14,46}$ Moreover, the reported degree of variability of the thoracic nerve roots, ranging from just 0.8 to $6.0 \mathrm{~mm}$ away from the inferior pedicle cortex, also has been cited to increase risk. ${ }^{13,62}$ Furthermore, the pedicles found in the thoracic region are not only smaller but also much more variable in size than those found in the lumbar region. ${ }^{13,62,63}$ Thus, because of the degree of variability and complexity of the structures found within the thoracic spine, the potential exists for increased risk of neurological complications during pedicle screw instrumentation. ${ }^{13,46}$

Although the aforementioned neurological complications are a concern, the incidence of adjacent-segment disease (ASD) after the completion of fusion surgery also deserves consideration. The prevalence of ASD after cervical and lumbar fusion surgery has been reported to be upward of $30 \% .^{1,2,10,19,24,25,29,39,41,55,61,67}$ Rajakumar et al. ${ }^{53}$ cited the prevalence of ASD 10 years after anterior cervical fusion to be approximately $25 \%$. Matsumoto et al. ${ }^{48}$ noted the incidence of ASD after lumbar spinal fusion to be up to $24 \%$ in symptomatic patients and radiological ASD to be present in $36 \%-84 \%$ of patients. Nevertheless, the development of ASD after fixation with thoracic pedicle screws has been addressed inadequately. As such, in this study, we reviewed the literature on ASD after pedicle screw fixation and report our experience with the thoracic spine specifically.

\section{Methods}

The online database PubMed (provided by the US National Library of Medicine at the National Institutes of Health) was used with appropriate Medical Subject Headings and the free subject terms "pedicle screw," "thoracic spine," and "adjacent segment disease." The following terms were combined interchangeably with the first 3 terms: "fusion," "fixation," "review," "therapy," "case report," "meta-analysis," and "complication." Selected references were used to provide descriptions of experiences regarding ASD after pedicle screw fixation. Additional references were obtained from articles that we reviewed.

\section{Institution Study Design}

To facilitate an analysis of spinal fusion and the incidence of complications, we performed a retrospective review of a prospectively maintained database that included 123 consecutive adult patients who underwent spinal fixation using thoracic pedicle screws. Pregnant or lactating females, children (under the age of 18 years), and prisoners were excluded. Therefore, 76 males and 47 females were included in this study. Preoperative diagnoses included degenerative disease, idiopathic scoliosis, multiple myeloma, kyphotic deformity, neurofibromatosis, epidural hematoma, pseudarthrosis, infection, intradural cyst, spondylotic myelopathy, herniated disc(s), congenital malformation, epidural tumor, iatrogenic deformity, and several types of trauma (i.e., motor vehicle accident, fall, assault, snowboarding or diving accident, and gunshot wound). Patients were evaluated preoperatively and postoperatively using standing 36-inch plain scoliosis radiography, CT, and/or MRI.

\section{Surgical Technique}

A posterior midline skin incision was made in the thoracic spine, and with the use of a subperiosteal dissection technique, the posterior elements of the operative segment were exposed bilaterally as far as the transverse processes. All surgeries were considered "open"; no minimally invasive surgeries were included in this study. Care was taken not to disrupt the adjacent interspinous ligaments or the zygapophyseal facet joint capsules above and below the levels of fusion. Laminectomies were performed using a combination of rongeurs and curettes to enable decompression of the spinal dura mater. Laminectomies were specifically avoided at the rostral and caudal extremes of the construct in an attempt to preserve sagittal alignment. Autologous bone graft was harvested from the iliac crest. In most cases, this bone was combined with bone removed during the posterior decompression. At this point, attention was directed to the stabilization portion of the system. Using the Expedium system (DePuy Spine), pedicle screws with polyaxial heads were placed at the operative thoracic levels bilaterally.

A high-speed drill was used to decorticate the bone at the entry point until cancellous bone was exposed. Afterward, a pedicle finder or a drill was used, followed by the use of a tap. The length of the hole was then explored with a ball-tipped probe to ensure that no cortical breach existed. After confirmation of the adequacy of the tapped tract, pedicle screws were placed. The screw diameters varied from 4.5 to $7.0 \mathrm{~mm}$. After screw placements, intraoperative fluoroscopy was performed to confirm appropriate alignment of the screws. When this alignment was confirmed, attention was directed to placement of the rods into the top-loading screws. The rods were approximated to the screws sequentially throughout the length of the construct to improve sagittal plane alignment of the operative thoracic segment. After all screws were secured to the rod and final tightening was performed, cross connectors typically were placed between the rods and secured to improve torsional and rotational stability. When this procedure was completed, a high-speed drill was used to decorticate the transverse processes of the vertebra in the 
operative segments. Bone graft material was packed into the lateral gutters, lateral to the instrumentation, to enable fusion to occur within the operative segments.

\section{Postoperative Assessment}

Each radiographic analysis was carried out by 2 independent radiologists (typically either a board-certified neuroradiologist or a bone radiologist). Preoperative and postoperative CT images were obtained for all patients and compared to elicit any indications of disease within or adjacent to the surgical construct (Figs. 1 and 2). Imaging also was performed at regular follow-up visits (routinely 6 weeks, 3 months, 6 months, 1 year, and 2 years) to evaluate for bony fusion and to look for the development of ASD. Patients were assessed using serial upright plain radiography. If indicated, additional follow-up examination and advanced imaging were performed.

\section{Results}

The 123 consecutive patients who met the inclusion criteria and underwent thoracic pedicle screw fixation were analyzed. Their mean age was 41 years (range 18-79 years). Of the 123 patients, definitive radiographic fusion was detected in 115 (93.5\%). In total, 1135 thoracic pedicle screws and 233 rods were placed. The number of levels included in the constructs ranged from 1 to 16 (arithmetic mean of 5). Seven incidences of instrumentation failure

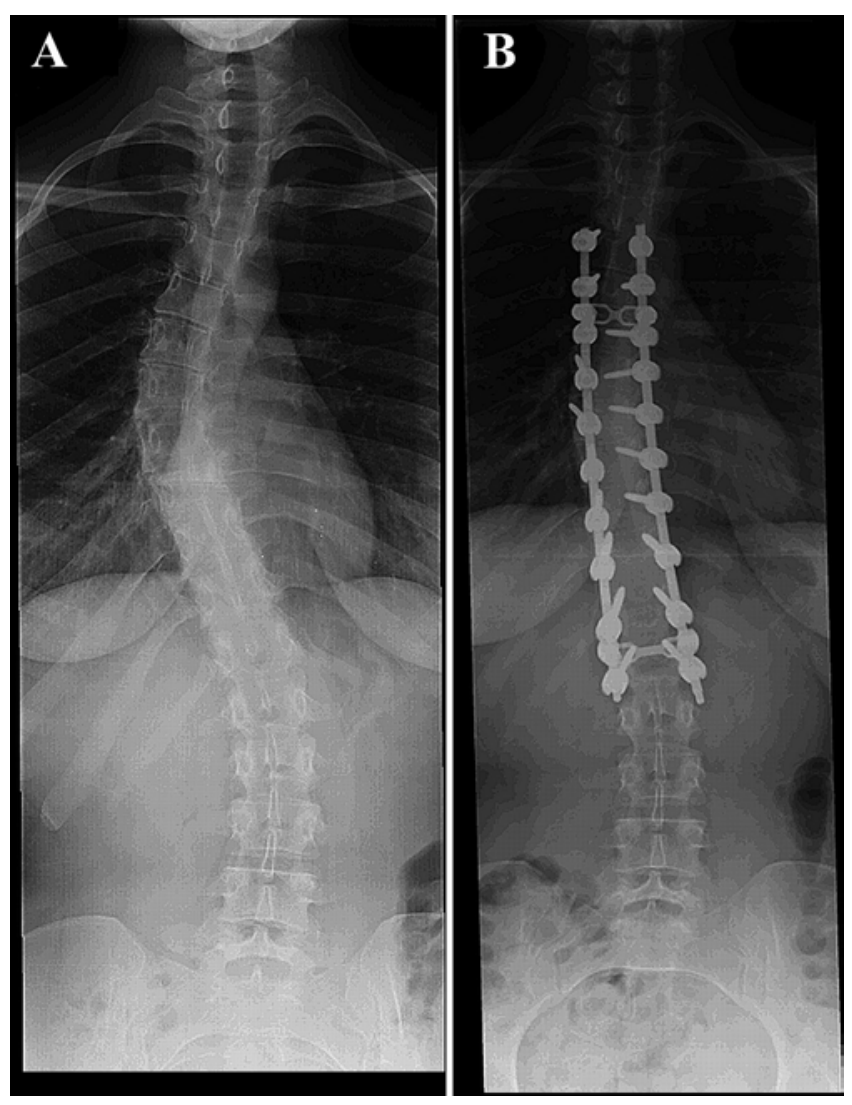

FIG. 1. Anteroposterior radiographs of a patient before $(\mathbf{A})$ and after $(\mathbf{B})$ thoracic pedicle screw fixation.

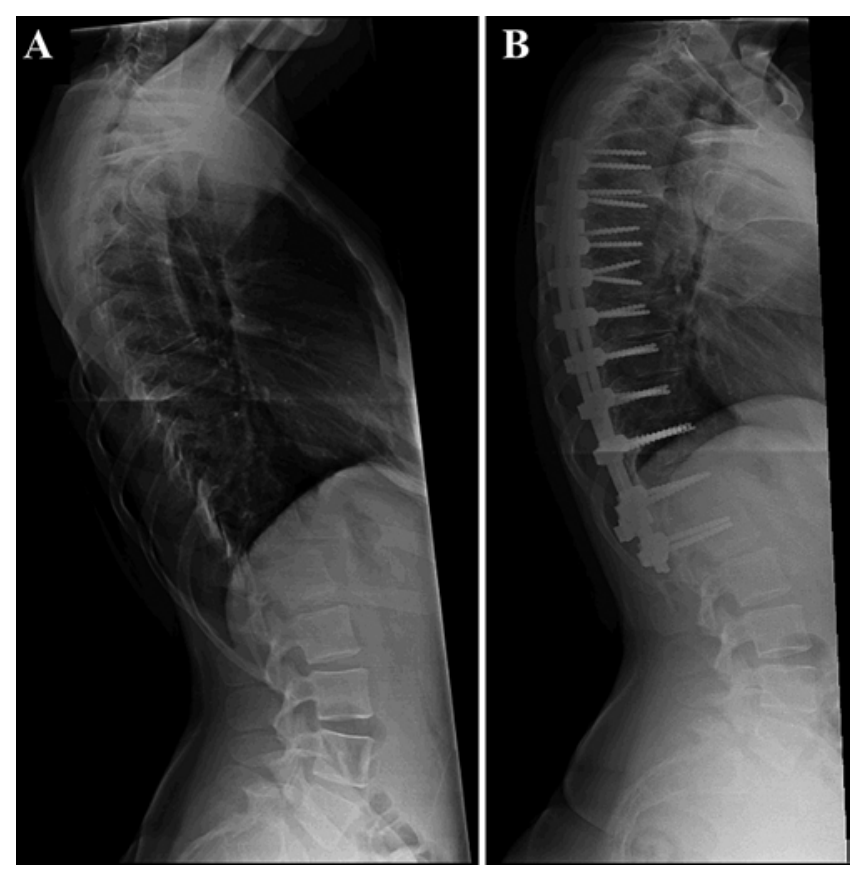

FIG. 2. Lateral radiographs of a patient before $(\mathbf{A})$ and after $(\mathbf{B})$ thoracic pedicle screw fixation. Note the preservation of normal sagittal plane balance in the postoperative image.

and 8 lucencies surrounding the screws were observed. Definitive ASD of the thoracic spine was observed in 1 patient. Overall, the patients underwent clinical and radiographic postoperative follow-up for a mean of 50 months (range 1-139 months) between the years 1996 and 2013; 10 patients were lost to follow-up before 12 months. In our subset analysis, the majority (10 of 14) of patients had a normal preoperative sagittal vertical axis (SVA) $(<50$ $\mathrm{mm})$, as measured using standing 36-inch plain scoliosis radiographs (Table 1).

\section{Discussion}

Spinal fixation has been used as a therapeutic modality for the past few decades, and pedicle screw fixation has been widely used for all types of fusion surgeries. Although pedicle screws have been used mostly for fixation in the lumbar spine, thoracic pedicle screws have also gained in popularity in fusion surgery. ${ }^{5,50,57,58,68}$ Various researchers and surgeons have asserted that thoracic pedicle screws are superior to hooks or wires as a result of their higher stiffness and better pullout strength and the improvements in control of thoracic and apical rotational capabilities and postsurgical clinical outcomes that they provide. ${ }^{6,15,34,36-38,46,56}$ However, some concerns regarding the use of pedicle screw fixation in the thoracic spine still remain. The incidence of ASD after fixation with thoracic pedicle screws has recently become a concern for those who undergo fusion surgery. $16,17,44,63,64$

Spinal fusion surgery causes a loss of motion at the fused levels of the spine, which is then compensated for by increased motion at the adjacent unfused segments. Because of the significant additional forces placed on the adjacent levels, ASD is not infrequently observed and can 
TABLE 1. Subgroup analysis of change in SVA compared with levels fused

\begin{tabular}{ccc}
\hline & \multicolumn{2}{c}{ SVA (mm) } \\
\cline { 2 - 3 } Levels Fused & Preop & Postop \\
\hline T3-L4 & -62 & -25 \\
\hline T12-L4 & -14 & 4 \\
\hline C7-T6 & -4 & -2 \\
\hline T5-10 & 23 & 33 \\
\hline C7-T5 & -31 & -28 \\
\hline T2-L1 & 41 & 8 \\
\hline T4-L1 & 39 & 36 \\
\hline C4-T7 & 69 & 59 \\
\hline T3-L4 & -65 & -17 \\
\hline T11-L4 & 1 & 0 \\
\hline T11-L4 & 14 & 1 \\
\hline T1-L2 & -37 & -2 \\
\hline T11-L3 & 63 & 13 \\
\hline T4-L4 & 24 & 16 \\
\hline
\end{tabular}

be a long-term repercussion of spinal fusion surgery. ${ }^{10,40}$ The creation of rigid motion at the fused levels essentially accelerates degeneration at the adjacent disc spaces. ${ }^{60}$

Data on the incidence of ASD after fixation with thoracic pedicle screws have been limited. For instance, Badra et al. $^{3}$ reported acute disc herniation at T4-5 with rapidly progressing paraplegia after T5-S1 instrumented fusion, whereas Oh et al. ${ }^{49}$ reported a similar disc herniation at T9-10 after T10-S1 instrumented fusion. Chalouhi et al. ${ }^{9}$ reported a T1-2 disc degeneration after anterior C7-T1 instrumented fusion, and Freccero and Donovan ${ }^{21}$ reported a T1-2 disc herniation after anterior C5-T1 fusion. This paucity of literature on ASD in the thoracic spine might support our findings that only 1 patient developed ASD after thoracic spinal fusion.

A handful of larger studies investigated both patient and surgical risk factors for the development of ASD after thoracolumbar or lumbar fusion. ${ }^{10}$ Patient-related risk factors include age ${ }^{2}$ obesity, sex, bone mineral density, preexisting degeneration of adjacent discs, and menopause. ${ }^{19}$ Previous studies proposed patient age to be a major risk factor for ASD. This suggestion originated from the findings of Aota et al., ${ }^{2}$ who indicated that post-lumbar fusion instability, which results in greater risk for the development of ASD, occurred significantly more frequently in older patients than in younger ones. However, this specific finding was disproven by more recent studies, ${ }^{1,19}$ which showed that the average age of patients with ASD did not differ significantly from the average age of those without ASD.

Surgical factors that can lead to an increased risk of ASD include the length of the fusion, radical decompression, stiffness of the construct, and loss of lumbar lordosis. ${ }^{39}$ Additional surgical risk factors that were categorized based on the use of MR images versus radiographs for identification were found by Lee et al. ${ }^{41}$ Risk factors that appeared on images produced by MRI included disc and facet degeneration of the adjacent segment. In contrast, risk factors found on images using radiographs included instability, rotational deformity, and disc wedging. Lee et al. ${ }^{41}$ suggested that although all of the aforementioned factors are commonly believed to increase risk for ASD, it was the facet degeneration, noticed on MR images, that correlated most significantly with a higher incidence of ASD. Toyone et al. ${ }^{61}$ reported that short-segment fixation without fusion for thoracolumbar burst fracture effectively preserved motion while preventing adjacent disc degeneration after 10 years of follow-up. The results of this study also need long-term clinical outcome follow-up, because long-term fixation without fusion can lead to delayed construct instability (which can have the unintended outcome of protecting against ASD).

Previous studies in which radiographic evidence was used to estimate the prevalence rate of ASD after lumbar fusion surgery found it to be approximately 30\%. Cheh et al. ${ }^{10}$ found an ASD rate of $30.3 \%$ in an average follow-up time of 7.8 years (range 5-16 years). After cervical spine fusion surgery, degeneration of the intervertebral discs that are located adjacent to the fused levels is said to occur in approximately $26 \%$ of patients within 10 years of the surgery. ${ }^{29}$ In our experience, 1 patient was observed in long-term radiographic and clinical follow-up to have ASD of the thoracic spine. Given that a supported rate of ASD after thoracic fusions has yet to be reported, future studies are encouraged to establish its incidence.

The correlation between the number of levels fused and the incidence of ASD has been the topic of another ongoing debate. In a study on ASD after lumbar/thoracolumbar fusion with pedicle screw instrumentation, Cheh et al. ${ }^{10}$ found, after a minimum of 5 years of follow-up, an increased incidence and severity of ASD as more levels were included in the fusion. Gillet ${ }^{25}$ published similar results from a separate study in which up to 4-level fusions were examined. Sears ${ }^{55}$ recently presented data showing the risk of ASD to be $1.7 \%$ for 1-level fusions, double that for 2-level fusions, and triple that for 3- or 4-level fusions. Still, controversy persists. In a study of patients with up to a 3-level fusion, Wiltse et al. ${ }^{67}$ found that the number of levels fused did not increase the incidence of ASD significantly. In yet another study, Ghiselli et al. ${ }^{24}$ found that patients who underwent a 1-level fusion were more likely to develop clinical ASD than those who underwent a multilevel fusion. ${ }^{52}$ Similarly, Hilibrand et al. ${ }^{29}$ found more incidences of ASD after 1-level cervical fusions than after multilevel arthrodesis. Given the aforementioned controversies, further study is required.

It should be noted that what is colloquially termed ASD in the cervical and lumbar spines includes the phenomenon of proximal junctional kyphosis (PJK) in the thoracic spine. Although studies have not focused on the incidence of PJK exclusively after thoracic pedicle screw fixation, some recent reviews reported the incidence of PJK after all spinal fusion surgeries. The authors of a systematic review reported the incidence of PJK to range from $17 \%$ to $39 \%$, and the majority of incidents occurred within 2 years of surgery. ${ }^{32}$ The authors of another meta-analysis, based on 14 studies, reported the incidence of PJK to be $30 \%$ (range 17\%-62\%). ${ }^{45}$ Other individual studies have found the incidence of PJK to be as low as 5.6\%. ${ }^{30}$ It is plausible 
that PJK after thoracic pedicle screw fixation is less common than after other types of fixation, given the anatomical support of the rib cage. This notion is supported by several studies that found the incidence of PJK to be lower for cases in which the upper-most instrumented vertebra was in the upper thoracic region. ${ }^{30,51,54}$ However, other studies found no difference in the incidence of PJK based on location of the upper-most instrumented vertebra. ${ }^{22,26,31}$

The occurrence of PJK also might be related to patient demographics and changes in spinopelvic parameters. Previous studies found increased rates of ASD, specifically PJK, in patients who underwent surgical correction and had a higher preoperative SVA. ${ }^{52}$ In our subset analysis, the majority of patients had a normal preoperative SVA (as measured on standing 36-inch plain scoliosis radiographs) (Table 1). Although a limitation in our study is that upright scoliosis radiographs to use for the determination of perioperative SVA were not available for all patients, normal preoperative SVA parameters and mild SVA changes might have contributed to our low rate of ASD and reoperation. Given that definitive ASD of the thoracic spine was observed in only 1 patient, the potential for subgroup analyses was nonexistent. However, we encourage future studies to analyze the relationship of preoperative diagnosis, age, body mass index, levels of fusion, and standardized patient outcomes on the occurrence of ASD. ${ }^{22,26,52}$

\section{Conclusions}

Our long-term radiographic follow-up evaluation revealed the use of pedicle screws for thoracic fixation to be an effective stabilization modality. The analysis of longterm patient outcomes showed the development of ASD in the thoracic spine in only 1 patient. It is our belief that preserving the adjacent-level facet joint capsules and the interspinous ligaments, and avoiding laminectomies at the extremes of the constructs, contributes to successful patient outcomes. We encourage further studies to establish the incidence of ASD after thoracic fusion and the influence of the number of levels fused on ASD.

\section{References}

1. Aiki H, Ohwada O, Kobayashi H, Hayakawa M, Kawaguchi S, Takebayashi T, et al: Adjacent segment stenosis after lumbar fusion requiring second operation. J Orthop Sci 10:490-495, 2005

2. Aota Y, Kumano K, Hirabayashi S: Postfusion instability at the adjacent segments after rigid pedicle screw fixation for degenerative lumbar spinal disorders. J Spinal Disord 8:464-473, 1995

3. Badra MI, Assaker R, Musharrafieh RS: Acute paraplegia secondary to thoracic disc herniation of the adjacent segment following thoracolumbar fusion and instrumentation. Asian Spine J 7:55-59, 2013

4. Barr SJ, Schuette AM, Emans JB: Lumbar pedicle screws versus hooks. Results in double major curves in adolescent idiopathic scoliosis. Spine (Phila Pa 1976) 22:1369-1379, 1997

5. Belmont PJ Jr, Klemme WR, Dhawan A, Polly DW Jr: In vivo accuracy of thoracic pedicle screws. Spine (Phila Pa 1976) 26:2340-2346, 2001

6. Bess RS, Lenke LG, Bridwell KH, Cheh G, Mandel S, Sides B: Comparison of thoracic pedicle screw to hook instru- mentation for the treatment of adult spinal deformity. Spine (Phila Pa 1976) 32:555-561, 2007

7. Boos N, Webb JK: Pedicle screw fixation in spinal disorders: a European view. Eur Spine J 6:2-18, 1997

8. Brown CA, Lenke LG, Bridwell KH, Geideman WM, Hasan SA, Blanke K: Complications of pediatric thoracolumbar and lumbar pedicle screws. Spine (Phila Pa 1976) 23:15661571,1998

9. Chalouhi N, Jabbour P, Knafo S, Abilahoud G: Adjacent segment degeneration at T1-T2: myth or reality? Clin Neurol Neurosurg 115:1921-1923, 2013

10. Cheh G, Bridwell KH, Lenke LG, Buchowski JM, Daubs MD, Kim Y, et al: Adjacent segment disease following lumbar/thoracolumbar fusion with pedicle screw instrumentation: a minimum 5-year follow-up. Spine (Phila Pa 1976) 32:2253-2257, 2007

11. Cotrel Y, Dubousset J, Guillaumat M: New universal instrumentation in spinal surgery. Clin Orthop Relat Res 227:1023, 1988

12. Delorme S, Labelle H, Aubin CE, de Guise JA, Rivard CH, Poitras B, et al: A three-dimensional radiographic comparison of Cotrel-Dubousset and Colorado instrumentations for the correction of idiopathic scoliosis. Spine (Phila Pa 1976) 25:205-210, 2000

13. Dhawan A, Klemme WR, Polly DW Jr: Thoracic pedicle screws: comparison of start points and trajectories. Spine (Phila Pa 1976) 33:2675-2681, 2008

14. Di Silvestre M, Parisini P, Lolli F, Bakaloudis G: Complications of thoracic pedicle screws in scoliosis treatment. Spine (Phila Pa 1976) 32:1655-1661, 2007

15. Dobbs MB, Lenke LG, Kim YJ, Kamath G, Peelle MW, Bridwell KH: Selective posterior thoracic fusions for adolescent idiopathic scoliosis: comparison of hooks versus pedicle screws. Spine (Phila Pa 1976) 31:2400-2404, 2006

16. Donovan DJ, Polly DW Jr, Ondra SL: The removal of a transdural pedicle screw placed for thoracolumbar spine fracture. Spine (Phila Pa 1976) 21:2495-2499, 1996

17. Ebraheim NA, Jabaly G, Xu R, Yeasting RA: Anatomic relations of the thoracic pedicle to the adjacent neural structures. Spine (Phila Pa 1976) 22:1553-1557, 1997

18. Esses SI, Sachs BL, Dreyzin V: Complications associated with the technique of pedicle screw fixation. A selected survey of ABS members. Spine (Phila Pa 1976) 18:2231-2239, 1993

19. Etebar S, Cahill DW: Risk factors for adjacent-segment failure following lumbar fixation with rigid instrumentation for degenerative instability. J Neurosurg 90 (2 Suppl):163-169, 1999

20. Farber GL, Place HM, Mazur RA, Jones DE, Damiano TR: Accuracy of pedicle screw placement in lumbar fusions by plain radiographs and computed tomography. Spine (Phila Pa 1976) 20:1494-1499, 1995

21. Freccero D, Donovan DJ: Adjacent segment degeneration at T1-T2 presenting as chest pain: case report. Spine (Phila Pa 1976) 30:E655-E657, 2005

22. Fujimori T, Inoue S, Le H, Schairer WW, Berven SH, Tay $\mathrm{BK}$, et al: Long fusion from sacrum to thoracic spine for adult spinal deformity with sagittal imbalance: upper versus lower thoracic spine as site of upper instrumented vertebra. Neurosurg Focus 36(5):E9, 2014

23. Gaines RW Jr: The use of pedicle-screw internal fixation for the operative treatment of spinal disorders. J Bone Joint Surg Am 82-A:1458-1476, 2000

24. Ghiselli G, Wang JC, Bhatia NN, Hsu WK, Dawson EG: Adjacent segment degeneration in the lumbar spine. J Bone Joint Surg Am 86-A:1497-1503, 2004

25. Gillet P: The fate of the adjacent motion segments after lumbar fusion. J Spinal Disord Tech 16:338-345, 2003

26. Ha Y, Maruo K, Racine L, Schairer WW, Hu SS, Deviren V, 
et al: Proximal junctional kyphosis and clinical outcomes in adult spinal deformity surgery with fusion from the thoracic spine to the sacrum: a comparison of proximal and distal upper instrumented vertebrae. J Neurosurg Spine 19:360-369, 2013

27. Halm H, Niemeyer T, Link T, Liljenqvist U: Segmental pedicle screw instrumentation in idiopathic thoracolumbar and lumbar scoliosis. Eur Spine J 9:191-197, 2000

28. Hamill CL, Lenke LG, Bridwell KH, Chapman MP, Blanke $\mathrm{K}$, Baldus C: The use of pedicle screw fixation to improve correction in the lumbar spine of patients with idiopathic scoliosis. Is it warranted? Spine (Phila Pa 1976) 21:1241-1249, 1996

29. Hilibrand AS, Carlson GD, Palumbo MA, Jones PK, Bohlman HH: Radiculopathy and myelopathy at segments adjacent to the site of a previous anterior cervical arthrodesis. J Bone Joint Surg Am 81:519-528, 1999

30. Hostin R, McCarthy I, O’Brien M, Bess S, Line B, BoachieAdjei $\mathrm{O}$, et al: Incidence, mode, and location of acute proximal junctional failures after surgical treatment of adult spinal deformity. Spine (Phila Pa 1976) 38:1008-1015, 2013

31. Kim HJ, Boachie-Adjei O, Shaffrey CI, Schwab F, Lafage $\mathrm{V}$, Bess S, et al: Upper thoracic versus lower thoracic upper instrumented vertebrae endpoints have similar outcomes and complications in adult scoliosis. Spine (Phila Pa 1976) 39:E795-E799, 2014

32. Kim HJ, Lenke LG, Shaffrey CI, Van Alstyne EM, Skelly AC: Proximal junctional kyphosis as a distinct form of adjacent segment pathology after spinal deformity surgery: a systematic review. Spine (Phila Pa 1976) 37 (22 Suppl):S144S164, 2012

33. Kim YJ, Lenke LG, Bridwell KH, Cho YS, Riew KD: Free hand pedicle screw placement in the thoracic spine: is it safe? Spine (Phila Pa 1976) 29:333-342, 2004

34. Kim YJ, Lenke LG, Cho SK, Bridwell KH, Sides B, Blanke $\mathrm{K}$ : Comparative analysis of pedicle screw versus hook instrumentation in posterior spinal fusion of adolescent idiopathic scoliosis. Spine (Phila Pa 1976) 29:2040-2048, 2004

35. Kim YJ, Lenke LG, Kim J, Bridwell KH, Cho SK, Cheh G, et al: Comparative analysis of pedicle screw versus hybrid instrumentation in posterior spinal fusion of adolescent idiopathic scoliosis. Spine (Phila Pa 1976) 31:291-298, 2006

36. Kuklo TR, Lenke LG, O’Brien MF, Lehman RA Jr, Polly DW Jr, Schroeder TM: Accuracy and efficacy of thoracic pedicle screws in curves more than 90 degrees. Spine (Phila Pa 1976) 30:222-226, 2005

37. Kuklo TR, Potter BK, Lenke LG, Polly DW Jr, Sides B, Bridwell KH: Surgical revision rates of hooks versus hybrid versus screws versus combined anteroposterior spinal fusion for adolescent idiopathic scoliosis. Spine (Phila Pa 1976) 32:2258-2264, 2007

38. Kuklo TR, Potter BK, Polly DW Jr, Lenke LG: Monaxial versus multiaxial thoracic pedicle screws in the correction of adolescent idiopathic scoliosis. Spine (Phila Pa 1976) 30:2113-2120, 2005

39. Kumar MN, Jacquot F, Hall H: Long-term follow-up of functional outcomes and radiographic changes at adjacent levels following lumbar spine fusion for degenerative disc disease. Eur Spine J 10:309-313, 2001

40. Lee CK, Langrana NA: Lumbosacral spinal fusion. A biomechanical study. Spine (Phila Pa 1976) 9:574-581, 1984

41. Lee CS, Hwang CJ, Lee SW, Ahn YJ, Kim YT, Lee DH, et al: Risk factors for adjacent segment disease after lumbar fusion. Eur Spine J 18:1637-1643, 2009

42. Lee SS, Lenke LG, Kuklo TR, Valenté L, Bridwell KH, Sides B, et al: Comparison of Scheuermann kyphosis correction by posterior-only thoracic pedicle screw fixation versus combined anterior/posterior fusion. Spine (Phila Pa 1976) 31:2316-2321, 2006
43. Liljenqvist UR, Halm HF, Link TM: Pedicle screw instrumentation of the thoracic spine in idiopathic scoliosis. Spine (Phila Pa 1976) 22:2239-2245, 1997

44. Liljenqvist UR, Link TM, Halm HF: Morphometric analysis of thoracic and lumbar vertebrae in idiopathic scoliosis. Spine (Phila Pa 1976) 25:1247-1253, 2000

45. Liu FY, Wang T, Yang SD, Wang H, Yang DL, Ding WY: Incidence and risk factors for proximal junctional kyphosis: a meta-analysis. Eur Spine J 25:2376-2383, 2016

46. Lonner BS, Auerbach JD, Estreicher MB, Kean KE: Thoracic pedicle screw instrumentation: the learning curve and evolution in technique in the treatment of adolescent idiopathic scoliosis. Spine (Phila Pa 1976) 34:2158-2164, 2009

47. Lonstein JE, Denis F, Perra JH, Pinto MR, Smith MD, Winter RB: Complications associated with pedicle screws. J Bone Joint Surg Am 81:1519-1528, 1999

48. Matsumoto T, Okuda S, Maeno T, Yamashita T, Yamasaki R, Sugiura T, et al: Spinopelvic sagittal imbalance as a risk factor for adjacent-segment disease after single-segment posterior lumbar interbody fusion. J Neurosurg Spine 26:435-440, 2017

49. Oh IS, Seo JY, Ha KY, Kim YC: Thoracic disc herniation of the adjacent segment with acutely progressing myelopathy. Asian Spine J 4:52-56, 2010

50. O’Brien MF, Lenke LG, Mardjetko S, Lowe TG, Kong Y, Eck K, et al: Pedicle morphology in thoracic adolescent idiopathic scoliosis: is pedicle fixation an anatomically viable technique? Spine (Phila Pa 1976) 25:2285-2293, 2000

51. O'Shaughnessy BA, Bridwell KH, Lenke LG, Cho W, Baldus C, Chang MS, et al: Does a long-fusion "T3-sacrum" portend a worse outcome than a short-fusion "T10-sacrum" in primary surgery for adult scoliosis? Spine (Phila Pa 1976) 37:884-890, 2012

52. Park SJ, Lee CS, Chung SS, Lee JY, Kang SS, Park SH: Different risk factors of proximal junctional kyphosis and proximal junctional failure following long instrumented fusion to the sacrum for adult spinal deformity: survivorship analysis of 160 patients. Neurosurgery 80:279-286, 2017

53. Rajakumar DV, Hari A, Krishna M, Konar S, Sharma A: Adjacent-level arthroplasty following cervical fusion. Neurosurg Focus 42(2):E5, 2017

54. Scheer JK, Lafage V, Smith JS, Deviren V, Hostin R, McCarthy IM, et al: Maintenance of radiographic correction at 2 years following lumbar pedicle subtraction osteotomy is superior with upper thoracic compared with thoracolumbar junction upper instrumented vertebra. Eur Spine J 24 (Suppl 1):S121-S130, 2015

55. Sears WR: Adjacent segment disease following 1049 posterior lumbar interbody fusions - a retrospective review. Spine J 10 (9 Suppl):S71-S72, 2010 (Abstract)

56. Suk SI, Kim WJ, Kim JH, Lee SM: Restoration of thoracic kyphosis in the hypokyphotic spine: a comparison between multiple-hook and segmental pedicle screw fixation in adolescent idiopathic scoliosis. J Spinal Disord 12:489-495, 1999

57. Suk SI, Kim WJ, Lee SM, Kim JH, Chung ER: Thoracic pedicle screw fixation in spinal deformities: are they really safe? Spine (Phila Pa 1976) 26:2049-2057, 2001

58. Suk SI, Lee CK, Kim WJ, Chung YJ, Park YB: Segmental pedicle screw fixation in the treatment of thoracic idiopathic scoliosis. Spine (Phila Pa 1976) 20:1399-1405, 1995

59. Suk SI, Lee CK, Min HJ, Cho KH, Oh JH: Comparison of Cotrel-Dubousset pedicle screws and hooks in the treatment of idiopathic scoliosis. Int Orthop 18:341-346, 1994

60. Throckmorton TW, Hilibrand AS, Mencio GA, Hodge A, Spengler DM: The impact of adjacent level disc degeneration on health status outcomes following lumbar fusion. Spine (Phila Pa 1976) 28:2546-2550, 2003

61. Toyone T, Ozawa T, Inada K, Shirahata T, Shiboi R, Wata- 
nabe A, et al: Short-segment fixation without fusion for thoracolumbar burst fractures with neurological deficit can preserve thoracolumbar motion without resulting in posttraumatic disc degeneration: a 10-year follow-up study. Spine (Phila Pa 1976) 38:1482-1490, 2013

62. Ugur HC, Attar A, Uz A, Tekdemir I, Egemen N, Genç Y: Thoracic pedicle: surgical anatomic evaluation and relations. J Spinal Disord 14:39-45, 2001

63. Vaccaro AR, Rizzolo SJ, Allardyce TJ, Ramsey M, Salvo J, Balderston RA, et al: Placement of pedicle screws in the thoracic spine. Part I: Morphometric analysis of the thoracic vertebrae. J Bone Joint Surg Am 77:1193-1199, 1995

64. Vaccaro AR, Rizzolo SJ, Balderston RA, Allardyce TJ, Garfin SR, Dolinskas C, et al: Placement of pedicle screws in the thoracic spine. Part II: An anatomical and radiographic assessment. J Bone Joint Surg Am 77:1200-1206, 1995

65. Vora V, Crawford A, Babekhir N, Boachie-Adjei O, Lenke L, Peskin M, et al: A pedicle screw construct gives an enhanced posterior correction of adolescent idiopathic scoliosis when compared with other constructs: myth or reality. Spine (Phila Pa 1976) 32:1869-1874, 2007

66. West JL III, Ogilvie JW, Bradford DS: Complications of the variable screw plate pedicle screw fixation. Spine (Phila Pa 1976) 16:576-579, 1991

67. Wiltse LL, Radecki SE, Biel HM, DiMartino PP, Oas RA, Farjalla G, et al: Comparative study of the incidence and severity of degenerative change in the transition zones after instrumented versus noninstrumented fusions of the lumbar spine. J Spinal Disord 12:27-33, 1999

68. Youkilis AS, Quint DJ, McGillicuddy JE, Papadopoulos SM:
Stereotactic navigation for placement of pedicle screws in the thoracic spine. Neurosurgery 48:771-779, 2001

69. Yuan HA, Garfin SR, Dickman CA, Mardjetko SM: A historical cohort study of pedicle screw fixation in thoracic, lumbar, and sacral spinal fusions. Spine (Phila Pa 1976) 19 (20 Suppl):2279S-2296S, 1994

70. Zindrick MR, Wiltse LL, Widell EH, Thomas JC, Holland WR, Field BT, et al: A biomechanical study of intrapeduncular screw fixation in the lumbosacral spine. Clin Orthop Relat Res (203):99-112, 1986

\section{Disclosures}

Research and support were received from DePuy Spine for the performance of this study.

\section{Author Contributions}

Conception and design: Heary, N Agarwal. Acquisition of data: Heary, N Agarwal. Analysis and interpretation of data: Heary, N Agarwal. Drafting the article: all authors. Critically revising the article: all authors. Reviewed submitted version of manuscript: all authors. Statistical analysis: N Agarwal, P Agarwal. Administrative/technical/material support: Heary. Study supervision: Heary.

\section{Correspondence}

Robert F. Heary, Department of Neurological Surgery, Rutgers New Jersey Medical School, 90 Bergen St., Ste. 8100, PO Box 1709, Newark, NJ 07101-1709. email: heary@njms.rutgers.edu. 